OPEN ACCESS

Edited by:

Luisa Martinez-Pomares,

University of Nottingham,

United Kingdom

Reviewed by:

Francisco J. Medrano,

Virgen del Rocío University Hospital,

Spain

Janet Willment,

University of Exeter, United Kingdom

${ }^{*}$ Correspondence:

Theodore J. Kottom

kottom.theodore@mayo.edu

Specialty section:

This article was submitted to

Molecular Innate Immunity,

a section of the journal

Frontiers in Immunology

Received: 19 October 2021 Accepted: 30 November 2021 Published: 16 December 2021

Citation:

Kottom TJ, Carmona EM and Limper AH (2021) Current State of

Carbohydrate Recognition and

C-Type Lectin Receptors in

Pneumocystis Innate Immunity.

Front. Immunol. 12:798214.

doi: 10.3389/fimmu.2021.798214

\section{Current State of Carbohydrate Recognition and C-Type Lectin Receptors in Pneumocystis Innate Immunity}

\author{
Theodore J. Kottom ${ }^{1,2 *}$, Eva M. Carmona ${ }^{1,2}$ and Andrew H. Limper ${ }^{1,2}$ \\ 1 Thoracic Diseases Research Unit, Departments of Medicine and Biochemistry, Mayo Clinic, Rochester, MN, United States, \\ ${ }^{2}$ Department of Laboratory Medicine and Pathology, Mayo Clinic, Rochester, MN, United States
}

Pneumocystis jirovecii is one of the most common fungal pathogens in immunocompromised individuals. Pneumocystis jirovecii pneumonia (PJP) causes a significant host immune response that is driven greatly by the organism's cell wall components including $\beta$-glucans and major surface glycoprotein (Msg). These ligands interact with a number of C-type lectin receptors (CLRs) leading to downstream activation of proinflammatory signaling pathways. This minireview provides a brief overview summarizing known CLR/ Pneumocystis interactions.

Keywords: beta-glucans, CLR, inflammation, Pneumocystis, pneumonia

\section{INTRODUCTION}

Pneumocystis jirovecii is the opportunistic fungal organism responsible for Pneumocystis jirovecii pneumonia (PJP) that causes severe morbidity and mortality in immunocompromised individuals and is one of the top 10 severe fungal infections in the world (1). Pneumocystis species are fungi that belong to the ascomycetes and have a diminutive trophic form and a larger cyst or asci form (2). Regarding the organism's cell wall, both forms possess abundant major surface glycoproteins (Msgs) also termed glycoprotein A (gpA) (the genomes of Pneumocystis spp. encode for an abundance of Msgs proteins compromising approximately $3-6 \%$ of the total genome) (3). This large multicopy family is thought to be important for host/organism interactions as well as evasion of the host immune response (3). The cyst form also contains substantial amounts of $\beta$-glucans (4), and the fungus has the required enzymes for the synthesis and degradation of $\beta-1,3-$ and $\beta-1,6$-linkages (4, 5). Furthermore, the Pneumocystis cell wall lacks chitin (3) a component of fungal organisms as well as $\alpha$-glucans which are present in a number of pathogenic and nonpathogenic fungal organisms (68). Lastly, Pneumocystis lacks hyper mannose glycosylation on its outer surface unlike other pathogenic fungi such as Candida albicans (9) and its low complex composition hypothesized as a way to avoid host immune detection (3).

The major Pneumocystis ligands $\beta$-glucans and Msgs, have been shown to interact with a number of known C-type lectin receptors (CLRs) and are discussed below (Figure $\mathbf{1}$ and Table 1). 


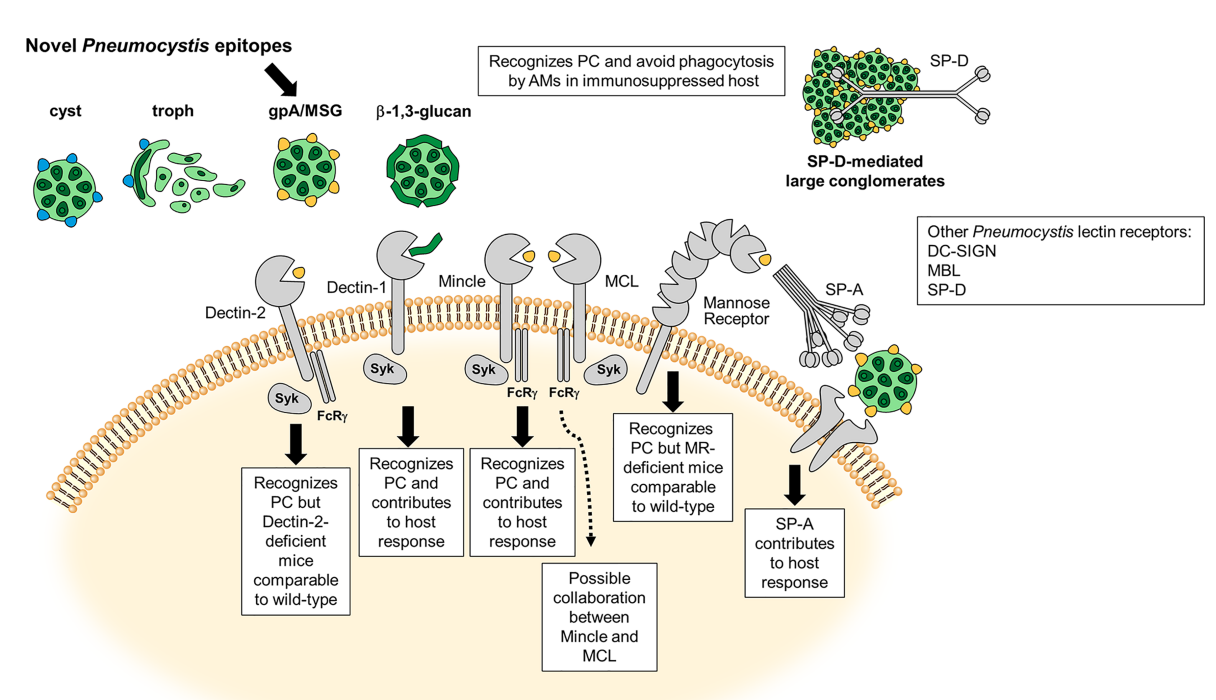

FIGURE 1 | Carbohydrate Recognition and C-type Lectin (CLR) Receptors in Pneumocystis (PC). Schematic illustration adapted from Hoving (10) of the most characterized carbohydrate recognition receptors for the fungal organism and brief description of the host response. Major surface glycoprotein (Msg) is a novel ligand on the Pneumocystis cell surface. The dotted line represents a possible connection with MCL and Mincle on inflammatory signaling in the presence of Pneumocystis Msg (11).

\section{DC-SIGN}

Dendritic Cell-Specific Intercellular adhesion molecule-3Grabbing Nonintegrin (DC-SIGN) is a CLR that has high affinity for fungal N-mannans $(9,35)$. Although highly recognized as an important CLR for many funga/host interactions, little is known about its role in Pneumocystis binding. Elsegeiny et al. showed that a human DC-SIGN Fc (fragment crystallizable) fusion could bind both cyst and trophic forms (15). This same lab shown that in immunodeficient humanized mice (huNOG-EXL) expressing high levels of DCSIGN mRNA, there were significantly lower fungal numbers in the immunosuppressed state, suggesting the importance of the CLR in organism burden control (14). We and others have shown through Fc fusions of the DC-SIGN CLR that the Msg on the surface of Pneumocystis serves as a ligand for DC-SIGN $(12,13)$. To date, no studies have evaluated mutations of the 7 known distinct genes encoding the human DC-SIGN homolog using the Pneumocystis pneumonia (PCP) mouse model to further study the relevance of these mutations in contributing to Pneumocystis innate immunity (36).

\section{DECTIN-1}

CLR Dectin-1 has long been considered the preeminent fungal $\beta$ glucan receptor (37). Its role in Pneumocystis host defense was

TABLE 1 | List of host immune receptors, their Pneumocystis ligands, presence in relevant cell types in PCP, and importance in host/Pneumocystis interactions or response.

\begin{tabular}{|c|c|c|c|c|}
\hline Receptor & Ligand & Cell Type & Importance & Reference \\
\hline Dectin-1 (CLEC7A) & B-1,3 glucan & $\begin{array}{l}\text { macrophages, dendritic cells (DCs), bronchial epithelial cells, pulmonary } \\
\text { epithelium }\end{array}$ & ++ & $(16-21)$ \\
\hline Dectin-2 (CLEC6A) & Msg/gpA & DCs, macrophages & + & $(12,22)$ \\
\hline Mincle (CLEC4E) & Msg/gpA & Monocytes, macrophages, neutrophils, DCs & ++ & $(12,16)$ \\
\hline MCL (CLEC4D) & Msg/gpA & Monocytes, macrophages, neutrophils, DCs & ++ (in vitro) & $(11,12)$ \\
\hline Mannose Binding Lectin (MBL) (COLEC1) & $\mathrm{Msg} / \mathrm{gpA}$ & plasma & ++ & $(23,24)$ \\
\hline Surfactant protein B (SP-B) & $\begin{array}{l}\text { (Binds } \\
\text { organism?) }\end{array}$ & Lung lavage fluids & * & (34) \\
\hline
\end{tabular}

++, strong evidence for importance in host response/interactions to Pneumocystis; +, moderate evidence for importance host response to Pneumocystis; +, involved in Pneumocystis host response/interactions weak or further studies needed; *host response/interactions to Pneumocystis unknown. 
first demonstrated through its importance in nonopsonized phagocytosis of the fungal organism by the alveolar macrophage (AM) in vitro (21). The receptor appears to colocalize (bind to the $\beta$-glucan carbohydrate linkages) with the fungal cell wall and is important in killing of Pneumocystis organisms. Furthermore, competitive inhibition studies with Saccharomyces cerevisiae $\beta$-glucan rather than mannan demonstrated that organism killing by AMs could be significantly reduced, providing more credence to the importance of Dectin-1 in the control of organism clearance by AMs (21). Other have also shown that Dectin-1 colocalizes with TLR2 and mannose receptor (MR) in AMs (discussed below) challenged with Pneumocystis organisms (17). In addition to the importance of Dectin-1 in Pneumocystis and AM identification and killing, the receptor has also been shown to be important in dendritic cell (DC) interactions with Pneumocystis. Studies conducted by Carmona et al. show that human DCs preincubated with a monoclonal antibody to Dectin-1, can significantly reduce TNFa when stimulated with Pneumocystis-specific $\beta$-glucans (38).

A number of studies examined the role of Dectin-1 using in vivo models of PCP. First, Saijo et al. demonstrated that in the PCP rodent model, Dectin-1-deficient mice displayed significantly more cysts than wild type mice in both immunocompetent and immunosuppressed models of PCP, being the first to link Dectin-1 with importance in controlling organism burden in PCP (19). Secondly, an eloquent study by Rapaka et al., demonstrated that when severe combined immunodeficiency (SCID) mice with PCP were given an adenoviral expressing a Fc-Dectin-1 fusion, the construct reduced overall organism burden and lung parameters associated with organism/host response damage (20). Furthermore, we and others have shown that in the mouse PCP model, total RNA samples from infected whole lungs as well as AMs derived directly from $P$. jirovecii-infected lungs express induced levels of Dectin-1 mRNA $(16,18)$. Taken together, the data support a critical role for Dectin-1 in innate immunity during PCP.

\section{DECTIN-2}

Dectin-2, another member of the CLR family, recognizes $\alpha$ mannan/mannose structures on the cell wall of fungal organisms $(39,40)$. Dectin-2 has been shown to form heterodimers with the CLR Macrophage C-type lectin (MCL) leading to greater inflammatory responses then receptor alone when binding to $\alpha$-mannans (41). We have shown that Dectin- 2 can significantly bind live Pneumocystis organisms using a Dectin-2 Fc fusion protein and that this binding could be significantly reduced when the fungi were heat-treated $\left(56^{\circ} \mathrm{C}\right.$ for 1 hour) (12). These data suggest that Dectin-2 recognizes $\alpha$-mannan/mannose structure (s) on the cell surface. Further experiments determined that Dectin-2 CLR may specifically bind a component(s) of native isolated Msg from Pneumocystis, as this Pneumocystis surface component significantly bound the Dectin-2 Fc fusion protein to a greater degree than the Fc control alone. Furthermore, RAW macrophages overexpressing full-length Dectin-2 demonstrated significantly greater binding of Pneumocystis organism compared to RAW cells treated with vector alone. Additionally, downstream spleen tyrosine kinase (Syk) activation following Dectin-2/Fc $\gamma$ ligation was severely blunted in Dectin-2 deficient compared to wild type macrophages (22). Despite these data supporting strong interactions and activation of Dectin-2 signaling following interactions of this CLR with Pneumocystis, it was surprising when we observed that immunocompetent and immunosuppressed Dectin-2 deficient mice demonstrated statistically similar organism burdens and cytokine production compared to wild type mice (22). Therefore, taken together these data suggest a role for Dectin-2 in Pneumocystis host response events, but this CLR may play limited roles in controlling organism burden during PCP.

\section{MINCLE/MCL}

Macrophage inducible $\mathrm{Ca}^{2+}$-dependent lectin receptor (Mincle) was first described in fungal/host interactions with Candida albicans (42). This CLR is considered more promiscuous in its ligand binding, with known interactions with Mycobacterium tuberculous trehalose-6,6'-dimycolate (TDM) (43), human cholesterol crystals (44), and fungal $\alpha$-mannose (45). Similar to Dectin-2, it has been shown that a Mincle Fc-fusion can significantly bind Pneumocystis Msg and that RAW macrophages overexpressing Mincle also bind more fungal organisms then the parent line alone. Furthermore, Mincle deficiency in macrophages also leads to decreased Syk phosphorylation, suggesting the importance of Mincle in the host downstream signaling proinflammatory response to Pneumocystis (16). However, unlike Dectin-2, in the PCP immunosuppressed model, Mincle knockout mice had considerably greater $(\sim 3 \mathrm{X})$ Pneumocystis organism burdens then their wild type counterparts, suggesting the importance of this CLR in organism clearance during PCP (16).

Macrophage C-type lectin (MCL) is a CLR with considerably homology to Dectin-2 and Mincle. Like Mincle, it is has been shown to also bind $\alpha$-mannose residues (46). Similar to what was reported for Mincle, MCL also binds Pneumocystis Msg in similar fashion when tested with the MCL Fc-fusion proteins as well as using whole organisms (12). One recent exciting finding was that silencing mRNA expression of both MCL and Mincle together in the RAW macrophage cell line prior to the overnight addition of Pneumocystis $\beta$-glucans and in the presence of Msg resulted in substantial reduction of TNF $\alpha$ secretion. Although individually silencing each CLR alone reduced TNF $\alpha$ considerably, their levels of inhibition did not achieve the synergistically reduced levels of the double silenced cell line (11). These data suggest the possible coregulation of the host immune response to Pneumocystis through Mincle-MCL CLR interdependent expression (47). Similar events have been described with these two receptors and the bacterial ligand mycobacterial cord factor (48). Future studies of the PCP 
mouse model in MCL/Mincle double deficient animals would be interesting to test the validity of this hypothesis.

\section{MANNOSE-BINDING LECTIN}

Mannose-binding lectin (MBL) is a soluble CLR shown to be important in innate immunity against fungi through activation of complement and participating in phagocytosis. Ligands for MBL include $\mathrm{N}$-acetylglucosamine linkages and mannose residues (49, 50). Studies to date report that MBL polymorphisms in HIVpatients confer more susceptibility to PJP (23). More recently it was determined that in another cohort of HIV-patients in Northern Thailand, MBL mutations resulting in low MBL expression had significantly higher incidence of PJP (24). Currently, potential Pneumocystis ligands for MBL are not yet known.

\section{MANNOSE RECEPTOR}

One of the first CLRs described to function as a myeloid receptor for Pneumocystis was the mannose receptor (MR) reported in the early 1990s. Ezekowitz and colleagues have shown that binding of Pneumocystis to AMs was competitively inhibited with mannose antagonists and that COS (CV-1 (simian) in Origin, and carrying the SV40 genetic material) (51) cells expressing human MR readily bound and engulfed Pneumocystis organisms, and that this phagocytosis required both transmembrane and cytoplasmic regions of the $\operatorname{MR}(29,30)$. Later, O'Riordan et al. identified Msg as a ligand for $\mathrm{MR}$, and utilizing a similar competitive assay with purified Msg as the soluble competitor, determined the importance of MR in mediating attachment of Pneumocystis to AMs (28). These studies led to a novel initial hypothesis that CLRs maybe used therapeutically in PJP (28). It was further shown that AMs from HIV positive individuals exhibited downregulated MR, potentially representing a contributing factor for impaired organism uptake by AMs that increases susceptibility to Pneumocystis jirovecii (27). From these observations, these researchers designed an MR-Fc fusion protein that, when incubated with Pneumocystis, increased phagocytic potential by greater than 8 -fold, suggesting a potential clinical tool for treating HIV MR-downregulated AMs (26).

Further evidence beyond MR roles in phagocytic and endocytic functions was reported by Zhang et al. and linked NF- $\kappa B$ activation with MR. Sugar competition assays as well as targeted siRNA of MR, resulted in significant reductions in NF$\mathrm{\kappa B}$ nuclear translocation when challenged with Pneumocystis, linking the proinflammatory response and MR to the organism (25). Although these in vitro data suggest importance of MR in PCP, immunocompetent and immunosuppressed mouse models of PCP reported no significant differences comparing wild type and MR knockout animals. These authors therefore concluded that the absence of this receptor may be redundant and that other receptor(s) may compensate for the receptor absence (52).

\section{OTHER NON-SIGNALING LECTIN BINDING PROTEINS}

\section{Surfactant Protein A}

Surfactant protein A (SP-A), was the first pulmonary surfactant proteins associated with binding to Pneumocystis, with purified SP-A being shown to bind to the mannose rich Msg component of the organism (53). This lectin was found to be in significantly greater quantities in all AIDS-related pneumonias including PJP (33). Later it was determined that SP-A specifically enhanced the attachment of Pneumocystis organisms to rat AMs (32). Others have shown that in normal human AMs, the presence of SP-A on the surface of Pneumocystis correlates with decreased organism phagocytosis and maybe a contributor to the pathogenesis of PJP (31). Linke et al. was the first to show that immunosuppressed SP-A deficient mice exhibited higher organism burden and higher histological score (percentage of alveolar involvement). These data led these researchers to suggest that SP-A is indeed needed for organism burden control and modulated AM inflammatory responses to the organism (54).

\section{Surfactant Protein B}

Studies regarding the role of another lung surfactant lectin, surfactant protein B (SP-B) are limited. Beers et al. showed that in the immunosuppressed mouse PCP model, SP-B is downregulated at both the mRNA and protein level. They concluded that this may be a pathogenic factor that the organism uses to prevent AMs from phagocytosing the organism (34).

\section{Surfactant Protein D}

Our lab performed a number of studies in the early 1990s examining the role of surfactant protein D (SP-D) in Pneumocystis host response. These studies revealed a number of main findings. As with SP-A, SP-D also accumulates in the lung during PCP (55) and is important for AM binding (56). Furthermore, as with SP-A, SP-D was found to bind the Msg component of the Pneumocystis cell wall (57). SP-D can also undergo different states of polymerization, with an increase in these events leading to greater aggregation of SP-D (58). Analyzing the various states of this collectin, we found that higher dodecameric forms of the protein bound fungal organisms significantly greater than the trimeric configuration of the protein (57). Furthermore, it was demonstrated that SP-D accumulations are high in animal models of PCP as well as those individuals with PJP $(59,60)$. As with SP-A, SP-D was proposed as a means by which the organism avoids host killing (61). Interestingly however, in the CD4-depleted PCP mouse model, SP-D deficient animals surprisingly showed significantly higher organisms burdens along with higher lung inflammation scores, and lung weights. The authors suggests that the potential difference they noted compared to the previous studies where SP-D accumulates in the lung resulting in fungal aggregates and reduced organism clearance, might be due to due to various stages of the host response over the course of infections that differentially regulates both pro- and anti-inflammatory responses to the organism over time (62). 


\section{Concluding Remarks}

Innate immune receptors and lectins/collectins are an important part of the armature of the host defense against fungal pathogenic infections. Typically, they bind fungal mannoproteins or carbohydrates embedding and/or lining the fungal cell wall (63). The prototypic fungal cell wall is composed of chitin, $\alpha$-glucans (both absent in Pneumocystis), $\beta-1,3$ and $\beta-1,6$ glucans, as well as a variety of low and high complex mannoproteins (64). CLRs and lectins bind their respective fungal ligands via their carbohydrate recognition domains (CRD) (65). Innate immune receptors bind their respective ligands resulting in downstream activation (via Syk phosphorylation, Protein kinase C alpha (PKC $\gamma$ ), Rat sarcoma virus (Ras)/Rapidly Accelerated Fibrosarcoma (Raf) for example), whereas collectins via binding the fungal ligand/organism help in macrophages phagocytosis and killing $(66,67)$. Currently, it is thought that there are more pattern recognition receptors (PRRs) (including CLRs and collectins) for fungi than any other organisms (68). This review is an attempt at highlighting the most current literature on carbohydrate recognition receptors involved in Pneumocystis organism/host cell interactions. Our understanding of the roles of specific lectins/receptors and the downstream inflammatory host response to Pneumocystis is still evolving. Host myeloid cells appear to have a high level of receptor/lectin redundancy in their identification and response to Pneumocystis, as individual absence of certain receptors is regarded as dispensable in regard to murine models of PCP (22, 52). In HIV/Pneumocystis co-infection, the role of these

\section{REFERENCES}

1. Brown GD, Denning DW, Gow NA, Levitz SM, Netea MG, White TC. Hidden Killers: Human Fungal Infections. Sci Transl Med (2012) 4 (165):165rv13. doi: 10.1126/scitranslmed.3004404

2. Truong J, Ashurst JV. StatPearls. Treasure Island (FL (2021).

3. Ma L, Chen Z, Huang da W, Kutty G, Ishihara M, Wang H, et al. Genome Analysis of Three Pneumocystis Species Reveals Adaptation Mechanisms to Life Exclusively in Mammalian Hosts. Nat Commun (2016) 7:10740. doi: $10.1038 /$ ncomms 10740

4. Kottom TJ, Limper AH. Cell Wall Assembly by Pneumocystis Carinii. Evidence for a Unique Gsc-1 Subunit Mediating Beta -1,3-Glucan Deposition. J Biol Chem (2000) 275(51):40628-34. doi: 10.1074/ jbc.M002103200

5. Kottom TJ, Hebrink DM, Jenson PE, Gudmundsson G, Limper AH. Evidence for Proinflammatory Beta-1,6 Glucans in the Pneumocystis Carinii Cell Wall. Infect Immun (2015) 83(7):2816-26. doi: 10.1128/IAI.00196-15

6. Konomi M, Fujimoto K, Toda T, Osumi M. Characterization and Behaviour of Alpha-Glucan Synthase in Schizosaccharomyces Pombe as Revealed by Electron Microscopy. Yeast (2003) 20(5):427-38. doi: 10.1002/yea.974

7. Sorais F, Barreto L, Leal JA, Bernabe M, San-Blas G, Nino-Vega GA. Cell Wall Glucan Synthases and GTPases in Paracoccidioides Brasiliensis. Med Mycol (2010) 48(1):35-47. doi: 10.3109/13693780802713356

8. Hogan LH, Klein BS. Altered Expression of Surface Alpha-1,3-Glucan in Genetically Related Strains of Blastomyces Dermatitidis That Differ in Virulence. Infect Immun (1994) 62(8):3543-6. doi: 10.1128/iai.62.8.35433546.1994

9. Cambi A, Netea MG, Mora-Montes HM, Gow NA, Hato SV, Lowman DW, et al. Dendritic Cell Interaction With Candida Albicans Critically Depends on N-Linked Mannan. J Biol Chem (2008) 283(29):20590-9. doi: 10.1074/ jbc.M709334200 carbohydrate recognizing molecules is largely unknown because of lack of representative animal models. For example, it has been published that CLRs can promote protective anti-viral responses and aid in viral transmission (69). In this scenario of fungal/viral coinfection, CLR responses could be vastly different in the host immune signaling and/or organism uptake and killing then the single organism PCP CD4-depleted infection model. Future studies utilizing combination of Pneumocystis CLR/lectin ligands such as Msg/ $\beta$-glucans and HIV envelope protein gp120 in in vivo assays with AMs and DCs might yield important early insights into the role this coinfection may play in the pathogenesis of HIV/ PJP. In closing, this minireview summarizes our understanding of the current information on the CLRs/lectins linked with Pneumocystis and myeloid cell interactions.

\section{AUTHOR CONTRIBUTIONS}

This mini-review was written by TJK, EMC, and AHL. All authors contributed to the article and approved the submitted version.

\section{FUNDING}

National Heart, Lung, and Blood Institute R01-HL62150-100\% funding source.

10. Hoving JC. Pneumocystis and Interactions With Host Immune Receptors PloS Pathog (2018) 14(2):e1006807. doi: 10.1371/journal.ppat.1006807

11. Kottom TJ, Hebrink DM, Carmona EM, Limper AH. Pneumocystis Carinii Major Surface Glycoprotein Dampens Macrophage Inflammatory Responses to Fungal Beta-Glucan. J Infect Dis (2020) 222(7):1213-21. doi: 10.1093/ infdis/jiaa218

12. Kottom TJ, Hebrink DM, Monteiro JT, Lepenies B, Carmona EM, Wuethrich M, et al. Myeloid C-Type Lectin Receptors That Recognize Fungal Mannans Interact With Pneumocystis Organisms and Major Surface Glycoprotein. J Med Microbiol (2019) 68(11):1649-54. doi: 10.1099/jmm.0.001062

13. Sassi M, Kutty G, Ferreyra GA, Bishop LR, Liu Y, Qiu J, et al. The Major Surface Glycoprotein of Pneumocystis Murina Does Not Activate Dendritic Cells. J Infect Dis (2018) 218(10):1631-40. doi: 10.1093/infdis/jiy342

14. Dai G, Wanek A, Eddens T, Volden P, Kolls JK. Toward a Humanized Mouse Model of Pneumocystis Pneumonia. JCI Insight (2021) 6(2):1-8. doi: 10.1172/ jci.insight. 139573

15. Elsegeiny W, Zheng M, Eddens T, Gallo RL, Dai G, Trevejo-Nunez G, et al. Murine Models of Pneumocystis Infection Recapitulate Human Primary Immune Disorders. JCI Insight (2018) 3(12):1-12. doi: 10.1172/ jci.insight.91894

16. Kottom TJ, Hebrink DM, Jenson PE, Nandakumar V, Wuthrich M, Wang H, et al. The Interaction of Pneumocystis With the C-Type Lectin Receptor Mincle Exerts a Significant Role in Host Defense Against Infection. J Immunol (2017) 198(9):3515-25. doi: 10.4049/jimmunol.1600744

17. Inoue M, Moriwaki Y, Arikawa T, Chen YH, Oh YJ, Oliver T, et al. Cutting Edge: Critical Role of Intracellular Osteopontin in Antifungal Innate Immune Responses. J Immunol (2011) 186(1):19-23. doi: 10.4049/jimmunol.1002735

18. Iriart X, Witkowski B, Courtais C, Abbes S, Tkaczuk J, Courtade M, et al. Cellular and Cytokine Changes in the Alveolar Environment Among Immunocompromised Patients During Pneumocystis Jirovecii Infection. Med Mycol (2010) 48(8):1075-87. doi: 10.3109/13693786.2010.484027 
19. Saijo S, Fujikado N, Furuta T, Chung SH, Kotaki H, Seki K, et al. Dectin-1 Is Required for Host Defense Against Pneumocystis Carinii But Not Against Candida Albicans. Nat Immunol (2007) 8(1):39-46. doi: 10.1038/ni1425

20. Rapaka RR, Goetzman ES, Zheng M, Vockley J, McKinley L, Kolls JK, et al. Enhanced Defense Against Pneumocystis Carinii Mediated by a Novel Dectin-1 Receptor Fc Fusion Protein. J Immunol (2007) 178(6):3702-12. doi: 10.4049/jimmunol.178.6.3702

21. Steele C, Marrero L, Swain S, Harmsen AG, Zheng M, Brown GD, et al. Alveolar Macrophage-Mediated Killing of Pneumocystis Carinii F. Sp. Muris Involves Molecular Recognition by the Dectin-1 Beta-Glucan Receptor. J Exp Med (2003) 198(11):1677-88. doi: 10.1084/jem.20030932

22. Kottom TJ, Hebrink DM, Jenson PE, Marsolek PL, Wuthrich M, Wang H, et al. Dectin-2 Is a C-Type Lectin Receptor That Recognizes Pneumocystis and Participates in Innate Immune Responses. Am J Respir Cell Mol Biol (2018) 58 (2):232-40. doi: 10.1165/rcmb.2016-0335OC

23. Yanagisawa K, Ogawa Y, Uchiumi H, Gohda F, Mawatari M, Ishizaki T, et al. Gene Polymorphisms of Mannose-Binding Lectin Confer Susceptibility to Pneumocystis Pneumonia in HIV-Infected Patients. J Infect Chemother (2015) 21(11):769-75. doi: 10.1016/j.jiac.2015.07.006

24. Yanagisawa K, Wichukchinda N, Tsuchiya N, Yasunami M, Rojanawiwat A, Tanaka $\mathrm{H}$, et al. Deficiency of Mannose-Binding Lectin Is a Risk of Pneumocystis Jirovecii Pneumonia in a Natural History Cohort of People Living With HIV/AIDS in Northern Thailand. PloS One (2020) 15(12): e0242438. doi: 10.1371/journal.pone.0242438

25. Zhang J, Zhu J, Imrich A, Cushion M, Kinane TB, Koziel H. Pneumocystis Activates Human Alveolar Macrophage NF-kappaB Signaling Through Mannose Receptors. Infect Immun (2004) 72(6):3147-60. doi: 10.1128/ IAI.72.6.3147-3160.2004

26. Stehle SE, Rogers RA, Harmsen AG, Ezekowitz RA. A Soluble Mannose Receptor Immunoadhesin Enhances Phagocytosis of Pneumocystis Carinii by Human Polymorphonuclear Leukocytes In Vitro. Scand J Immunol (2000) 52 (2):131-7. doi: 10.1046/j.1365-3083.2000.00755.x

27. Koziel H, Eichbaum Q, Kruskal BA, Pinkston P, Rogers RA, Armstrong MY, et al. Reduced Binding and Phagocytosis of Pneumocystis Carinii by Alveolar Macrophages From Persons Infected With HIV-1 Correlates With Mannose Receptor Downregulation. J Clin Invest (1998) 102(7):1332-44. doi: 10.1172/JCI560

28. O'Riordan DM, Standing JE, Limper AH. Pneumocystis Carinii Glycoprotein A Binds Macrophage Mannose Receptors. Infect Immun (1995) 63(3):779-84. doi: 10.1128/iai.63.3.779-784.1995

29. Kruskal BA, Sastry K, Warner AB, Mathieu CE, Ezekowitz RA. Phagocytic Chimeric Receptors Require Both Transmembrane and Cytoplasmic Domains From the Mannose Receptor. J Exp Med (1992) 176(6):1673-80. doi: 10.1084/ jem.176.6.1673

30. Ezekowitz RA, Williams DJ, Koziel H, Armstrong MY, Warner A, Richards FF, et al. Uptake of Pneumocystis Carinii Mediated by the Macrophage Mannose Receptor. Nature (1991) 351(6322):155-8. doi: 10.1038/351155a0

31. Koziel H, Phelps DS, Fishman JA, Armstrong MY, Richards FF, Rose RM. Surfactant Protein-A Reduces Binding and Phagocytosis of Pneumocystis Carinii by Human Alveolar Macrophages In Vitro. Am J Respir Cell Mol Biol (1998) 18(6):834-43. doi: 10.1165/ajrcmb.18.6.3059

32. Williams MD, Wright JR, March KL, Martin WJ2nd. Human Surfactant Protein A Enhances Attachment of Pneumocystis Carinii to Rat Alveolar Macrophages. Am J Respir Cell Mol Biol (1996) 14(3):232-8. doi: 10.1165/ ajrcmb.14.3.8845173

33. Sternberg RI, Whitsett JA, Hull WM, Baughman RP. Pneumocystis Carinii Alters Surfactant Protein A Concentrations in Bronchoalveolar Lavage Fluid. J Lab Clin Med (1995) 125(4):462-9.

34. Beers MF, Atochina EN, Preston AM, Beck JM. Inhibition of Lung Surfactant Protein B Expression During Pneumocystis Carinii Pneumonia in Mice. J Lab Clin Med (1999) 133(5):423-33. doi: 10.1016/S0022-2143(99)90019-7

35. Goyal S, Castrillon-Betancur JC, Klaile E, Slevogt H. The Interaction of Human Pathogenic Fungi With C-Type Lectin Receptors. Front Immunol (2018) 9:1261. doi: 10.3389/fimmu.2018.01261

36. Tanne A, Ma B, Boudou F, Tailleux L, Botella H, Badell E, et al. A Murine DCSIGN Homologue Contributes to Early Host Defense Against Mycobacterium Tuberculosis. J Exp Med (2009) 206(10):2205-20. doi: 10.1084/jem.20090188

37. Brown GD, Gordon S. Immune Recognition. A New Receptor for BetaGlucans. Nature (2001) 413(6851):36-7. doi: 10.1038/35092620
38. Carmona EM, Vassallo R, Vuk-Pavlovic Z, Standing JE, Kottom TJ, Limper AH. Pneumocystis Cell Wall Beta-Glucans Induce Dendritic Cell Costimulatory Molecule Expression and Inflammatory Activation Through a Fas-Fas Ligand Mechanism. J Immunol (2006) 177(1):459-67. doi: 10.4049/ jimmunol.177.1.459

39. Saijo S, Ikeda S, Yamabe K, Kakuta S, Ishigame H, Akitsu A, et al. Dectin-2 Recognition of Alpha-Mannans and Induction of Th17 Cell Differentiation Is Essential for Host Defense Against Candida Albicans. Immunity (2010) 32 (5):681-91. doi: 10.1016/j.immuni.2010.05.001

40. McGreal EP, Rosas M, Brown GD, Zamze S, Wong SY, Gordon S, et al. The Carbohydrate-Recognition Domain of Dectin-2 Is a C-Type Lectin With Specificity for High Mannose. Glycobiology (2006) 16(5):422-30. doi: 10.1093/ glycob/cwj077

41. Zhu LL, Zhao XQ, Jiang C, You Y, Chen XP, Jiang YY, et al. C-Type Lectin Receptors Dectin-3 and Dectin-2 Form a Heterodimeric Pattern-Recognition Receptor for Host Defense Against Fungal Infection. Immunity (2013) 39 (2):324-34. doi: 10.1016/j.immuni.2013.05.017

42. Wells CA, Salvage-Jones JA, Li X, Hitchens K, Butcher S, Murray RZ, et al. The Macrophage-Inducible C-Type Lectin, Mincle, Is an Essential Component of the Innate Immune Response to Candida Albicans. J Immunol (2008) 180(11):7404-13. doi: 10.4049/jimmunol.180.11.7404

43. Matsunaga I, Moody DB. Mincle Is a Long Sought Receptor for Mycobacterial Cord Factor. J Exp Med (2009) 206(13):2865-8. doi: 10.1084/jem.20092533

44. Kiyotake R, Oh-Hora M, Ishikawa E, Miyamoto T, Ishibashi T, Yamasaki S. Human Mincle Binds to Cholesterol Crystals and Triggers Innate Immune Responses. J Biol Chem (2015) 290(42):25322-32. doi: 10.1074/jbc.M115.645234

45. Yamasaki S, Matsumoto M, Takeuchi O, Matsuzawa T, Ishikawa E, Sakuma $\mathrm{M}$, et al. C-Type Lectin Mincle Is an Activating Receptor for Pathogenic Fungus, Malassezia. Proc Natl Acad Sci USA (2009) 106(6):1897-902. doi: 10.1073/pnas.0805177106

46. Lee RT, Hsu TL, Huang SK, Hsieh SL, Wong CH, Lee YC. Survey of ImmuneRelated, Mannose/Fucose-Binding C-Type Lectin Receptors Reveals Widely Divergent Sugar-Binding Specificities. Glycobiology (2011) 21(4):512-20. doi: 10.1093/glycob/cwq193

47. Miyake Y, Masatsugu OH, Yamasaki S. C-Type Lectin Receptor MCL Facilitates Mincle Expression and Signaling Through Complex Formation. J Immunol (2015) 194(11):5366-74. doi: 10.4049/jimmunol.1402429

48. Lobato-Pascual A, Saether PC, Fossum S, Dissen E, Daws MR. Mincle, the Receptor for Mycobacterial Cord Factor, Forms a Functional Receptor Complex With MCL and FcepsilonRI-Gamma. Eur J Immunol (2013) 43 (12):3167-74. doi: 10.1002/eji.201343752

49. Nadesalingam J, Dodds AW, Reid KB, Palaniyar N. Mannose-Binding Lectin Recognizes Peptidoglycan via the N-Acetyl Glucosamine Moiety, and Inhibits Ligand-Induced Proinflammatory Effect and Promotes Chemokine Production by Macrophages. J Immunol (2005) 175(3):1785-94. doi: 10.4049/jimmunol.175.3.1785

50. Sealy PI, Garner B, Swiatlo E, Chapman SW, Cleary JD. The Interaction of Mannose Binding Lectin (MBL) With Mannose Containing Glycopeptides and the Resultant Potential Impact on Invasive Fungal Infection. Med Mycol (2008) 46(6):531-9. doi: 10.1080/13693780801961329

51. Gluzman Y. SV40-Transformed Simian Cells Support the Replication of Early SV40 Mutants. Cell (1981) 23(1):175-82. doi: 10.1016/0092-8674(81)90282-8

52. Swain SD, Lee SJ, Nussenzweig MC, Harmsen AG. Absence of the Macrophage Mannose Receptor in Mice Does Not Increase Susceptibility to Pneumocystis Carinii Infection In Vivo. Infect Immun (2003) 71(11):6213-21. doi: 10.1128/IAI.71.11.6213-6221.2003

53. Zimmerman PE, Voelker DR, Mccormack FX, Palsrud JR, Martin WJ. 120-Kd Surface Glycoprotein of Pneumocystis-Carinii Is a Ligand for Surfactant Protein-A. J Clin Invest (1992) 89(1):143-9. doi: 10.1172/JCI115554

54. Linke MJ, Harris CE, Korfhagen TR, McCormack FX, Ashbaugh AD, Steele P, et al. Immunosuppressed Surfactant Protein A-Deficient Mice Have Increased Susceptibility to Pneumocystis Carinii Infection. J Infect Dis (2001) 183 (6):943-52. doi: 10.1086/319252

55. Limper AH, O’Riordan DM, Vuk-Pavlovic Z, Crouch EC. Accumulation of Surfactant Protein D in the Lung During Pneumocystis Carinii Pneumonia. J Eukaryot Microbiol (1994) 41(5):98S.

56. O'Riordan DM, Standing JE, Kwon KY, Chang D, Crouch EC, Limper AH. Surfactant Protein D Interacts With Pneumocystis Carinii and Mediates 
Organism Adherence to Alveolar Macrophages. J Clin Invest (1995) 95 (6):2699-710. doi: 10.1172/JCI117972

57. Vuk-Pavlovic Z, Standing JE, Crouch EC, Limper AH. Carbohydrate Recognition Domain of Surfactant Protein D Mediates Interactions With Pneumocystis Carinii Glycoprotein A. Am J Respir Cell Mol Biol (2001) 24 (4):475-84. doi: 10.1165/ajrcmb.24.4.3504

58. Crouch EC. Surfactant Protein-D and Pulmonary Host Defense. Respir Res (2000) 1(2):93-108. doi: 10.1186/rr19

59. Yong SJ, Vuk-Pavlovic Z, Standing JE, Crouch EC, Limper AH. Surfactant Protein D-Mediated Aggregation of Pneumocystis Carinii Impairs Phagocytosis by Alveolar Macrophages. Infect Immun (2003) 71(4):166271. doi: 10.1128/IAI.71.4.1662-1671.2003

60. Schmidt R, Markart P, Ruppert C, Temmesfeld B, Nass R, Lohmeyer J, et al. Pulmonary Surfactant in Patients With Pneumocystis Pneumonia and Acquired Immunodeficiency Syndrome. Crit Care Med (2006) 34(9):23706. doi: 10.1097/01.CCM.0000234036.19145.52

61. Brummer E, Stevens DA. Collectins and Fungal Pathogens: Roles of Surfactant Proteins and Mannose Binding Lectin in Host Resistance. Med Mycol (2010) 48(1):16-28. doi: 10.3109/13693780903117473

62. Atochina EN, Gow AJ, Beck JM, Haczku A, Inch A, Kadire H, et al. Delayed Clearance of Pneumocystis Carinii Infection, Increased Inflammation, and Altered Nitric Oxide Metabolism in Lungs of Surfactant Protein-D Knockout Mice. J Infect Dis (2004) 189(8):1528-39. doi: 10.1086/383130

63. Vendele I, Willment JA, Silva LM, Palma AS, Chai W, Liu Y, et al. Mannan Detecting C-Type Lectin Receptor Probes Recognise Immune Epitopes With Diverse Chemical, Spatial and Phylogenetic Heterogeneity in Fungal Cell Walls. PloS Pathog (2020) 16(1):e1007927. doi: 10.1371/journal.ppat.1007927

64. Garcia-Rubio R, de Oliveira HC, Rivera J, Trevijano-Contador N. The Fungal Cell Wall: Candida, Cryptococcus, and Aspergillus Species. Front Microbiol (2019) 10:2993. doi: 10.3389/fmicb.2019.02993
65. Hoving JC, Wilson GJ, Brown GD. Signalling C-Type Lectin Receptors, Microbial Recognition and Immunity. Cell Microbiol (2014) 16(2):185-94. doi: $10.1111 / \mathrm{cmi} .12249$

66. Borriello F, Zanoni I, Granucci F. Cellular and Molecular Mechanisms of Antifungal Innate Immunity at Epithelial Barriers: The Role of C-Type Lectin Receptors. Eur J Immunol (2020) 50(3):317-25. doi: 10.1002/eji.201848054

67. Kerrigan AM. And Brown GD. C-Type Lectins and Phagocytosis. Immunobiology (2009) 214(7):562-75. doi: 10.1016/j.imbio.2008.11.003

68. Kirkland TN, Fierer J. Innate Immune Receptors and Defense Against Primary Pathogenic Fungi. Vaccines (Basel) (2020) 8(2):1-21. doi: 10.3390/vaccines8020303

69. Monteiro JT, Lepenies B. Myeloid C-Type Lectin Receptors in Viral Recognition and Antiviral Immunity. Viruses (2017) 9(3):1-22. doi: $10.3390 /$ v9030059

Conflict of Interest: The authors declare that the research was conducted in the absence of any commercial or financial relationships that could be construed as a potential conflict of interest.

Publisher's Note: All claims expressed in this article are solely those of the authors and do not necessarily represent those of their affiliated organizations, or those of the publisher, the editors and the reviewers. Any product that may be evaluated in this article, or claim that may be made by its manufacturer, is not guaranteed or endorsed by the publisher.

Copyright (c) 2021 Kottom, Carmona and Limper. This is an open-access article distributed under the terms of the Creative Commons Attribution License (CC BY). The use, distribution or reproduction in other forums is permitted, provided the original author(s) and the copyright owner(s) are credited and that the original publication in this journal is cited, in accordance with accepted academic practice. No use, distribution or reproduction is permitted which does not comply with these terms. 